\title{
Les dones i la recopilació del Cançoner popular de Mallorca, del P. Rafel Ginard i Bauçà
}

\author{
Pere Rosselló Bover \\ Universitat de les Illes Balears \\ pere.rossello@uib.cat
}

\begin{abstract}
RESUM
Aquest treball pretén estudiar quin va ser el paper de les dones en la conservació del cançoner popular mallorquí i en la recol-lecció que el P. Rafel Ginard Bauçà va dur a terme i que va donar lloc als quatre volums del Cançoner popular de Mallorca, publicats entre 1966 i 1975. Alhora hi estudiam també les opinions de Ginard envers la marginació de la dona i també sobre l'antifeminisme que observa en moltes de les poesies populars.
\end{abstract}

PARAULES CLAU

cançoner; poesia de transmissió oral; informadors, feminisme: Rafel Ginard Bauçà

\begin{abstract}
This article examines the role played by women in preserving Majorca's folk song heritage and in the anthology of these songs compiled by P. Rafel Ginard Bauçà, which resulted in the four volumes of the Cançoner Popular de Mallorca published between I966 and I975. The article also studies Ginard's views on the marginalisation of women and the antifeminism that he observes in many of the folk songs.
\end{abstract}

KEYWORDS

folk songs; orally transmitted poetry; informants; feminism; Rafel Ginard Bauçà

REBUT: I9-O7-2OI7 | ACCEPTAT: 30-07-2OI7 


\section{Introducció}

No ens proposam estudiar aquí com apareix la dona en el Cançoner popular de Mallorca, recollit pel P. Rafel Ginard i Bauçà (Sant Joan, I899-Artà, I976). Aquesta tasca ja la va dur a terme Caterina Valriu (2008) i s'emmarcaria més bé en el que s'ha denominat —encara que sigui referint-se a la cultura popular actual, difosa a través dels mitjans de comunicació- «imatges de la dona» (Hollows 2005; Clúa 2008). L'objectiu que ens hem fixat és esbrinar quin fou el paper de les dones en la recopilació del Cançoner popular de Mallorca duta a terme pel P. Rafel Ginard, així com en la conservació i transmissió generacional del cançoner a l'illa de Mallor-

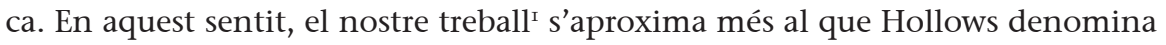
«feminisme folklòric»:

En él se privilegian las formas y prácticas culturales femeninas «auténticas» por encima de la cultura popular producida comercialmente y se intenta desenterrar una tradición cultural de las mujeres que ha permanecido escondida, marginada o trivializada por una tradición cultural masculina y/o una cultura femenina «no auténtica» (Hollows 2005: 23).

El primer que hem de remarcar és l'actitud oberta que Ginard, sobretot en comparació amb la majoria dels homes del seu temps, tenia envers la dona i la seva oposició a l'antifeminisme. Potser algunes tendències del feminisme actual veurien en la seva actitud davant els problemes de la dona un exemple de paternalisme i, en el fons, una actitud també masclista, que tendiria a continuar conservant la posició hegemònica de la masculinitat (Ibeas I998: I-5). Tanmateix, en la nostra opinió i sense negar una possible crítica d'aquest tipus, si consideram el context social i cultural en què Ginard es va formar i va viure, ens sembla que el seu pensament era molt més avançat que el de la major part de la societat. En les seves memòries d'infantesa, titulades De com era infant, que no varen veure la llum fins al 2003, hi trobam algunes reflexions força interessants sobre aquesta qüestió. Per exemple, veiem com Ginard comprenia la marginació secular de la dona i com la condemnava rotundament:

Tinc reparat a voltes, la manera desdenyosa i despectiva amb què els homes parlen de les dones com si elles, en general, no fossin infinitament millors. Això són restes de paganisme i barbàrie, com ho fou el fet que, a un Concili fins i tot, qualcú disputàs, dubtant, sobre si les dones tenien ànima, és a dir, si eren racionals. I si elles, de fet, ens són inferiors per la ciència i per l'art, no en tindran els homes la culpa que les han fetes viure postergades sigles i sigles, com si just servissen d'element decoratiu (Ginard 2003: I09).

No tenim, tanmateix, gaire textos de Ginard sobre el tema de la dona com per poder definir d'una manera més detallada la seva actitud davant el feminisme. Així, ens resulta impossible emmarcar el seu posicionament entre les diverses actituds dels homes davant els avenços dels drets de les dones dins un esquema com el dibuixat per Luis Bonino Méndez (I998), tot i que és clar que cal situar-lo

I No veiem que el nostre objecte de treball encaixi en cap de les quatre grans modalitats d'anàlisi de la cultura popular des del feminisme que Clúa, tot seguint Rakow, assenyala: «I) el análisis de las imágenes de la mujer producidas por la cultura popular; 2) la recuperación y relectura de la cultura popular creada por mujeres; 3) el estudio de la recepción y consumo de la cultura popular por parte de las mujeres, y 4) la formulación de una teoría cultural feminista» (Clúa 2008: 2I-22). 
en el grup dels homes partidaris dels canvis favorables per a les dones i oposat del «fonamentalisme masculí». Tanmateix, ens hem de situar en un moment força diferent del present i davant un personatge que pertanyia al clergat. I hem de pensar que seria difícil trobar homes del seu temps amb unes idees tan clares i tan avançades sobre la secular postergació de la dona, en una època en què el feminisme era més tost incipient en països com els Estat Units, amb una participació masculina paradoxal i/o conflictiva (Herrero I998). Potser aquesta valoració positiva de la dona li ve donat per l'admiració que sentia envers les figures femenines del seu entorn familiar més proper: la seva mare i la seva germana. Com ja veurem més endavant, la seva mare va ser una de les fonts importants per al seu primer coneixement del cançoner popular i per a la posterior recopilació de les cançons tradicionals mallorquines. Per altra part, la relació amb la seva germana fou molt intensa i, per aquest motiu, li dedicà De com era infant amb aquests mots: «A la meva germana Maria, "mon altre jo", un pom de flors marcides del jardí desolat de la meva infantesa» (Ginard 2003: 3I).

Ginard ens diu que sa mare fou una de les principals fonts d'on va beure per conèixer la llengua viva del poble. Ens conta que era una dona molt conversadora, que «xerra pels colzes i té una conversa molt agradosa i pintoresca, amb imatges i comparacions populars, amb frases i refranys i acudits», tot i ser analfabeta. Aquesta manca d'estudis és, precisament, el que li havia permès mantenir un llenguatge pur i ric, no contaminat, del qual el folklorista s'havia de nodrir:

Quantes vegades jo, llapis en mà, m'he passat llargues estones escoltant i prenent notes d'aquell doll interminable de paraules. Basta que l'escoltin. Molt de pics he desitjat saber taquigrafia per reproduir exactament el que diu, per la bellesa del llenguatge. A ella li crida molt l'atenció que, al temps que me parla, jo escriga. És que el cor no em basta per deixar perdre aquelles maneres de dir tan elegants, tan vívides i fresques (Ginard 2003: 44).

Ginard reconeix la importància que els pares — i bona part de la família- varen tenir en el seu primer contacte amb el cançoner popular i en la posterior tasca de recopilació de les cançons del poble:

Mon pare i ma mare, que Déu tinga, sabien cançons a balquena, a no acabar mai, i ells, amb la comportívola i amable actitud que sols els pares saben adoptar, foren la inexhaurible pedrera d'on vaig extreure els primers materials. Tota la nostra parentela, pagesa de sol a arrel, era també una vena inestroncable de cançons (Ginard I98I: 40).

Això no obstant, aquest coneixement que el nostre autor adquirí en la infantesa no es limitava només a les cançons populars, sinó que s'estenia a moltes altres tradicions (oracions, invocacions, llegendes, tradicions, etc.), algunes de les quals sovint gairebé fregaven el llindar de la superstició:

D'infant, encara vaig esser a temps a experimentar aquesta atmosfera, tan favorable al folklore. La meva mare m'ensenyà oracions populars, a repetir en colgar-me; oracions per invocar Santa Bàrbara els dies de trons i llamps; el Sant Traspàs de la Verge; la ingènua llegenda de la trobada per un pastor, de la Mare de Déu del poble; i me féu repetir la vida glosada del Bon Jesús, «Santa Rita anava a Missa» i la codolada grotesca,

Sant Vicenç Ferrer

treia aigo amb un paner (Ginard I98I: 72). 
Una d'aquestes supersticions populars, per exemple, era la prohibició d'«apuntar amb el dit les carabasses, perquè la carabassera tirava el fruit» (Ginard I98I: 75). Una altra era la de les oracions a Santa Bàrbara en les nits de tempesta per protegir-se de la fúria dels llamps:

¿I com explicaria el meu pànic, en les nits tempestuoses, esqueixades de trons i esquitxades de llamps, quan la caseta, feble com una closca de nou, semblava, amb aquell estabeig, que s'havia d'esquerdar? Quants de parenostres! Llavors sí que sortia l'oració de Santa Bàrbara! I la mare, a cada verga de llamp: «Senyau-vos», ens deia. I una llanternada blavenca se filtrava per les retxilleres (Ginard I98I: 80).

I no hi falten costums o activitats dels temps de la seva infantesa, els primers anys del segle xx, després completament perduts i àdhuc oblidats. És el cas de la recerca de «pedaços per baratar amb sal i cireres» (Ginard I98I: 83), que solien dur a terme les dones. Tot això ens revela el valor que per a Rafel Ginard han tengut les dones en la conservació del patrimoni de les tradicions culturals més diverses.

\section{Les dones, «tresoreres» del cançoner}

Per la seva experiència com a folklorista, per la intensa labor en la recopilació de les cançons populars, Rafel Ginard constata en diverses ocasions que les dones han estat les principals tresoreres de l'immens cabal de cançons conservat a Mallorca, ja que l'han guardat en la memòria i l'han transmès generació rere generació. En aquest sentit, el rol que les societats tradicionals van atorgar a la dona en l'educació dels fills va afavorir que fossin elles les que ensenyassin aquestes tradicions als infants. L'experiència de Ginard, per tant, vendria a corroborar que la cultura popular és una cultura feminitzada (Clúa 2008: 24), en la qual la dona ha tengut un paper molt important com a consumidora i com a transmissora alhora, encara que no sabem si també com a creadora. Tanmateix, més que no les persones amb cultura, fou el poble illetrat, els pagesos sobretot, els que varen transmetre el patrimoni del cançoner. La transmissió de les cançons dels pares als fills es duia a terme com un fet gairebé inconscient, juntament amb molts d'altres ensenyaments pràctics. A més, les cançons estaven vinculades quasi sempre a les feines de la llar i del camp, en les quals les dones humils també participaven intensament. Ginard, conscient de la importància que les dones han tengut en aquest procés de transmissió i de conservació, fins i tot no dubta a apuntar que potser les dones estan dotades de més bona memòria que no pas els homes, per la qual cosa recorden més i millor les cançons populars:

En arribar, cal primer de tot aclarir qui són, a cada indret sotmès a exploració folklòrica, els millors exemplars en el ram cançonístic. Gairebé sense excepció, les persones que saben més cançons i les diuen més acuradament, tenen un instint més fi de la mesura sil·làbica i les reciten, sense travelar, amb uns mots més llecorosos i sintaxi més nostra, són els analfabets. La gent analfabeta i humil ha estat l'arxiu fidelíssim del nostre Cançoner.

I, entre aquesta gent, són les dones les que, per tradició oral, han salvat un més considerable volum de cançons. Les dones canten més que no els homes. Elles canten triant bessó, collint oliva, cosint, brodant o feinejant 
dins la casa, bressolant els seus menuts i en totes les feines de foravila. La musa popular és femenina de nom i de fets. Cançons curtes, aiximateix hi ha molts d'homes que en saben, però les dones en saben encara més, i llavors, tenen l'exclusiva de les cançons llargues. Pareix que les dones són més afavorides de memòria que no els homes i que la memòria és típicament femenina (Ginard I98I: I9-20).

Ginard, per tant, constata que les dones solen saber més cançons i que tenen una major capacitat per recordar les més extenses, mentre que els homes en saben menys i les que saben són més breus. El folklorista mallorquí vincula el cant a les feines del camp i de la llar, però n'exclou fer bugada, una labor altre temps exclusivament femenina, en què diu que les dones no cantaven. Precisament aquesta feina, que implicava que les dones es reunissin amb altres dones, no donava lloc al cant perquè «No hi havia temps de cantar» i perquè solia propiciar la conversa i el safareig — comentari en què potser algú pugui veure una certa crítica a les donesque no pas els esplais lírics:

Però, en fer bugada, no canten, perquè «el dimoni i tot no hi trobà tonada», segons la dita popular. Les dones, primer, com que hi havia pocs dipòsits d'aigua als pobles, se reunien, per rentar, a la vora de qualque pou públic, a les piques dispostes pel comú, sota una porxada, i allà, tot donant puny a la roba i rallant pels colzes, sortien les braguetes de tothom. No hi havia temps de cantar. Les bugaderes tenen, ja de vell, fama de murmuradores (Ginard I98I: I9-20).

Així doncs, encara que les dones sàpiguen més cançons que no els homes, això no significa que la tasca de recollir-ne de la seva boca fos fàcil. Així, Ginard es refereix als nombrosos tabús i prejudicis que obstaculitzaven que les dones li diguessin cançons en les seves expedicions com a folklorista. És el cas de determinades cançons, a les quals s'atribuïen qualitats curatives o màgiques, que hom considerava que no es podien repetir sense que perdessin aquestes propietats extraordinàries. El recopilador del cançoner mallorquí explica la negativa a contar aquestes cançons, sobretot per culpa de la superstició femenina — fruit de la manca d'estudis i de l'educació rebuda-, la qual cosa ens diu que alguna vegada ho solucionava tot apel-lant al secret de confessió:

No obstant, en certs casos, m'he topat amb dones provectes que sabien cançons que m'interessaven de veres. Aquestes persones, pregades per mi, se guardaven obstinadament per a elles, algunes cançons, objecte d'especial recerca de part nostra. El motiu de retenir-les era que, entre els camperols, hi ha una creència supersticiosa. Determinades cançons no se poden repetir sense culpa. Les consideren subjectes, sota inviolable llei, a secret. -El misteri, l'arcà, el fer estar endarrer, donen importància a coses que la perdrien a plena llum-. Si són cançons o fórmules de curar malalties, diguem-ne per art d'encantament, aquelles cançons, si se comuniquen a altri, perden, segons creuen, la seva virtut curativa.

Doncs, en certes ocasions, hem hagut fins i tot d'apellar a la decisiva autoritat que el confés exercia sobre les persones a qui ens referim, a fi que deposassin la resistència, els fugís el pànic i m'obrissin el seu intern arxiu folklòric (Ginard I98I: 23). 
Vet aquí que un dels principals obstacles amb què el compilador es trobava provenia precisament dels prejudicis d'aquells que tenien un cert nivell cultural. Així, els que més coartaven les dones d'aportar cançons al folklorista solien ser els fills, que ja havien rebut una certa educació. Ginard ens parla d'«homes de carrera» que no deixen que les seves mares o germanes li contin cançons i critica especialment aquests homes que ho saben tot a força de no saber res, perquè pensen que el tresor popular no té cap valor (Ginard I98I: 24-25). I ens posa alguns exemples de dones joves que, amb arguments plens de prejudicis, impedeixen que les seves mares li ensenyin cançons:

O se us esdevé d'haver de conferir amb una senyora saberuda que us vol donar entenent que el folklore no té cap importància, i plena d'autosuficiència, vol burlar-se'n — no reflexionant que, amb una mica d'enginy i uns pessics de malicia, se poden burlar de totes les coses.

O heu d'haver-les amb qualque filla, pintada i depilada, que, clar i llampant, envest sa mare que us diu cançons: «Ma mare! ¿No veis que se'n riuen de vós?»... (Ginard I98I: 32).

Igualment, es queixa d'aquells que, tot volent esmenar les cançons, les afollen o dels que les transcriuen amb ortografies aberrants.

Quant a les persones concretes que més cançons populars li varen donar a conèixer, i que considera que tenien una memòria prodigiosa, esmenta especialment el seu pare i «Madò Catalina Caldereta, llubinera, veïna de Sineu, també sigui al cel» (Ginard I98I: 26). Just ells dos, amb alguns altres, li proporcionaren més de mil cançons. Ginard confessa que es trobà amb freqüència amb «persones que sabien moltíssimes cançons, i se bastaven elles mateixes per dar-nos què escriure, [...] sobretot dones» (Ginard I98I: 26-27). Una altra vegada, per tant, ens confirma la idea segons la qual les dones saben més cançons que no els homes. Així, en el parell d'anècdotes que conta sobre la seva experiència com a recol·lector de cançons, les dones no sols hi són presents, sinó que en són les protagonistes (Ginard I98I: 28-29).

\section{Les col-laboradores del Cançoner popular de Mallorca}

Ginard no va arribar a publicar la relació dels seus col-laboradors i informadors en la recol-lecció del cançoner popular de Mallorca. No ho féu per temor a oblidar noms, perquè en els inicis de la seva feina no apuntava els noms de les persones que li aportaven cançons. Tanmateix, entre els seus papers, va deixar dues llistes amb els noms de les persones que li havien proporcionat material del cançoner: el quadern Fitxes del cançoner popular de Mallorca, on els col-laboradors van ordenats per localitats, i un altre quadern titulat Col-laboradors del "Cançoner popular de Mallorca» i persones que han dites cançons pel mateix cançoner, també ordenat per localitats i datat a Llucmajor el I95 (Rosselló I999: 233-248). Encara que segurament aquestes dues llistes són incompletes, ens poden servir de punt de partida per conèixer, aproximadament, quina fou l'aportació de les dones en la recollida del cançoner. A partir d'aquestes dades hem elaborat el quadre següent, on es pot veure quina fou la participació femenina en la recol-lecció del Cançoner popular de Mallorca: 
Les dones i la recopilació del Cançoner popular de Mallorca, del P. Rafel Ginard i Bauçà

\begin{tabular}{|c|c|c|c|}
\hline MUNICIPI & $\begin{array}{l}\text { NOMBRE TOTAL DE } \\
\text { COL } \cdot L A B O R A D O R S \\
\end{array}$ & $\begin{array}{l}\text { NOMBRE DE DONES } \\
\text { COL·LABORADORES }\end{array}$ & $\%$ \\
\hline Alaró & I & $\mathrm{O}$ & $\mathrm{OO}, \mathrm{0O}$ \\
\hline Algaida & 8 & 5 & 62,50 \\
\hline S'Alqueria Blanca & 2 & $\mathrm{O}$ & $\mathrm{OO}, \mathrm{OO}$ \\
\hline Andratx & I & $\mathrm{O}$ & $\mathrm{OO}, \mathrm{OO}$ \\
\hline Ariany & 23 & 6 & 26,08 \\
\hline Artà & 5 & 4 & 80,00 \\
\hline Bunyola & $\mathrm{I} 3$ & 3 & 23,07 \\
\hline Búger & 4 & I & 25,00 \\
\hline Calvià & $\mathrm{I}$ & $\mathrm{o}$ & oo,oo \\
\hline Campanet & 3I & $\mathrm{I} 2$ & 38,70 \\
\hline Campos & 5 & 2 & 40,00 \\
\hline Consell & 5 & 3 & 60,00 \\
\hline Costitx & I & I & IOO,O \\
\hline Estallencs & 2 & I & 50,00 \\
\hline Felanitx & 4 & 2 & 50,00 \\
\hline Galilea & $\mathrm{I}$ & I & IOO,O \\
\hline Gènova (Palma) & 2 & I & 50,00 \\
\hline S'Horta & $\mathrm{I}$ & $\mathrm{I}$ & $\mathrm{IOO}, \mathrm{O}$ \\
\hline Inca & 8 & I & $\mathrm{I} 2,5 \mathrm{O}$ \\
\hline Sant Joan & $\mathrm{I} 2$ & 8 & 66,66 \\
\hline Sant Jordi (Palma) & $\mathrm{I}$ & $\mathrm{O}$ & OO,OO \\
\hline Lloseta & 9 & 3 & 33,33 \\
\hline Llubí & 42 & I8 & 42,85 \\
\hline Llucmajor & 28 & $\mathrm{I} 4$ & 50,00 \\
\hline Manacor & 7 & 4 & $57, \mathrm{I} 4$ \\
\hline Mancor & 2 & 2 & IOO,O \\
\hline Maria & 3 & I & 33,33 \\
\hline Montuïri & 4 & $\mathrm{I}$ & 25,00 \\
\hline Moscari & 2 & $\mathrm{O}$ & $\mathrm{OO}, \mathrm{OO}$ \\
\hline Muro & 37 & $\mathrm{I} 4$ & 37,83 \\
\hline Palma & 9 & 2 & 22,22 \\
\hline Petra & I5 & 9 & 60,00 \\
\hline Pla de na Tesa & I & I & IOO,O \\
\hline Pina & 7 & 3 & 42,85 \\
\hline Sa Pobla & 5 & $\mathrm{O}$ & $\mathrm{OO}, \mathrm{0O}$ \\
\hline Pollença & I & $\mathrm{O}$ & $\mathrm{OO}, \mathrm{OO}$ \\
\hline Porreres & 5 & I & 20,00 \\
\hline Pòrtol & 2 & I & 50,00 \\
\hline Puigpunyent & 2 & 2 & $\mathrm{IOO}, \mathrm{O}$ \\
\hline
\end{tabular}




\begin{tabular}{|c|c|c|c|}
\hline MUNICIPI & $\begin{array}{l}\text { NOMBRE TOTAL DE } \\
\text { COL } \cdot \text { LABORADORS }\end{array}$ & $\begin{array}{l}\text { NOMBRE DE DONES } \\
\text { COL·LABORADORES }\end{array}$ & $\%$ \\
\hline Randa & $\mathrm{I}$ & $\mathrm{I}$ & IOO,O \\
\hline Ses Salines i sa Colònia de Sant Jordi & 2 & $\mathrm{O}$ & $\mathrm{OO}, \mathrm{OO}$ \\
\hline Sencelles & I & $\mathrm{o}$ & $\mathrm{OO}, \mathrm{OO}$ \\
\hline Santa Maria & 3 & I & 33,33 \\
\hline Santanyí & I8 & II & 6I,II \\
\hline Selva & II & 4 & 36,36 \\
\hline Son Serra de Marina & I & $\mathrm{O}$ & $\mathrm{OO}, \mathrm{OO}$ \\
\hline Son Servera & I & I & IOO,O \\
\hline Sineu & 9 & 7 & 77,77 \\
\hline Sóller & $\mathrm{I} 4$ & 6 & 42,85 \\
\hline Vilafranca & $\mathrm{I} 4$ & 5 & $35,7 \mathrm{I}$ \\
\hline $\begin{array}{l}\text { Altres (Barcelona i altres llocs no } \\
\text { especificats) }\end{array}$ & 4 & o & $\mathrm{oo,oo}$ \\
\hline TOTALS & $39 I$ & I65 & 42,19 \\
\hline
\end{tabular}

Com veiem, encara que sols es tracti d'una mostra, el nombre de col-laboradors i d'informadors és, en la majoria de casos, masculí. Però això no significa necessàriament que els homes li aportassin més cançons que les dones, fet que no podem saber. Si tenim en compte que els primers contactes que Ginard solia establir en arribar a un poble eren amb els eclesiàstics i amb els escolans, a partir dels quals arribava a les persones i les famílies que li podien proporcionar cançons, és lògic que hi figurin més homes que dones. Tot i això, cal dir que una participació femenina d'un $42 \%$ és força considerable. A més, la quantitat de cançons aportades pels informadors són molt diferents. Com hem vist, uns pocs individus li proporcionaren centenars de cançons i d'altres, potser, sols unes poques.

\section{Refús de l'antifeminisme del cançoner}

La dona com a tema i com a protagonista és molt present també en el cançoner popular de Mallorca. Ja hem dit que aquest no era el nostre objecte d'estudi. Caterina Valriu ja va treballar aquesta qüestió i, per tant, ens remetrem a les seves paraules, amb què constata com les cançons populars reflecteixen unes determinades concepcions de la dona:

[...] la dona que hi trobem reflectida és la dona viva i quotidiana, que les cançons ens mostren molts d'aspectes de la realitat femenina — dels seus interessos, preocupacions i somnis- que les imposicions socials han soterrat. Hi trobem un model de dona allunyat de la dama angelicata $\mathrm{o}$ de la femme fatale que la literatura culta ha consagrat com a estereotip de la feminitat. Una dona que és capaç de fer sentir la veu, una veu pròpia, a voltes marcada per les convencions socials però en altres ocasions alliberada de traves i, per això mateix, directa, lliure i expressiva. En les cançons de les dones se'ns fa palesa una de les principals funcions de la poesia popular: donar veu als qui no tenen veu, obrir canals expressius a aquells que troben tancades les portes de l'alta cultura, convertir la pa- 
raula —-més enllà dels sentits literals - en un joc expressiu enriquidor, que estableix ponts de complicitat i d'enriquiment emocional entre els membres d'una mateixa comunitat. [...] Les gloses de dones, fetes o protagonitzades per dones, conformen un calidoscopi en el qual - a través dels vidrets acolorits de les paraules - podem entreveure tot un univers femení, ric, complex i bategant (Valriu 2008: 354-355).

Efectivament, la literatura popular, com la culta, reflecteix una ideologia i tendeix a perpetuar uns models determinants, per la qual cosa el feminisme ha d'acostar-se als estudis culturals, en els quals hem d'incloure els treballs sobre literatura tradicional i/o folklore. Ginard era conscient que la imatge femenina que el cançoner mallorquí oferia era esbiaixada i plena de prejudicis. Aquests prejudicis són els que la societat ha tengut i encara té envers les dones. Alguns pensadors, com Leo Lowenthal, han considerat que la cultura popular - entesa en un sentit ampli, que engloba també activitats culturals modernes com el còmic, el cinema, etc.— «está marcada por el estereotipo, el conservadurismo político, la manipulación de los bienes de consumo, y por afirmar que su finalidad es despolitizar a las masas, limitando sus expectativas sociales y económicas a un marco de explotación y opresión capitalistas» (Clúa 2008: I5). No ens ha d'estranyar que l'actual feminisme sovint percebi - tot seguint Berty Friedan i Susan Faludi- la cultura popular «como un campo instrumentalizado por el patriarcado para transmitir a las mujeres estereotipos opresores y modelos de feminidad muy restrictivos» (González i Clúa 2oIr: 8). Ginard s'adona d'aquest fet i, per aquest motiu, dedica tot un capítol de l'assaig El cançoner popular de Mallorca a l'antifeminisme que observa en el cançoner. És realment lloable que, en un treball en què hauria pogut obviar aquest tema, li dediqui un apartat sencer. El nostre folklorista comença constatant la universalitat d'aquest masclisme i l'explica pel fet que la literatura, com tants d'altres fets socials, ha estat sempre en mans dels homes:

Capítol de les al-lotes. Un les morreja i l'altre les defensa. Llavors, el primer les remunta i el segon les capfica. Finalment, tots dos demanen perdó de les bromes feixugues que han gastades contra les dones.

En la literatura de totes les edats que, quasi en absolut, és producte masculí, abunden — per això mateix — les diatribes antifeministes, a vegades d'una extremada virulència. Com és bo de comprendre, aquestes diatribes han trobat un llarg eco dins la literatura popular, de què són les glosades una notable característica.

Per amor d'aquest antifeminisme, difós dins els pobles, i que potser ja té el seu origen en nostra mare Eva, sol ésser sempre d'èxit segur, allà on hi ha homes, parlar contra les dones (Ginard I98I: II4).

Ginard pensa que l'antifeminisme és molt present en les cançons populars perquè les diatribes contra les dones solen tenir un èxit assegurat i, per tant, els glosadors se n'aprofiten per tal d'obtenir l'èxit del públic:

Entre els dos sexes, existeix, més o menys a les clares, un estat de guerra permanent. En el fons, no s'acaben d'entendre. I els homes — qui sap! — per dissimular que se preocupen de les dones, disfressen, tal vegada, de menyspreu, la seva preocupació. Sovint, als homes no els sol plaure pas- 
sar per sentimentals. Els poetes populars saben tot això i, aposta, per més fàcilment triomfar, se n'aprofiten (Ginard I98I: II4-II5).

Per il.lustrar la presència d'aquesta actitud contra les dones en el cançoner mallorquí, el nostre folklorista en posa un exemple:

\title{
De la graciosa cançó:
}

Ses al-lotes són traïdores que no ho poden esser més: com s'han menjades ses móres, diuen mal d'es romeguers,

se'n féu un comentari amb quatre dècimes, que se són popularitzades i que nosaltres transcriguérem de viva veu. La primera fa així:

A quinze anys, vaig començar a insultar qualque fadrina. Qui jove se determina, s'arriba a desenganar.

Totes ses dones que hi ha són gàbies enganadores. No vui pobres ni senyores, sempre vui estar fadrí, des que ma mare em va dir: «ses alllotes són traïdores».

La glosada està per finir. Els rapsodes s'aixequen drets i canten les dues darreres cançons, tot desitjant que visquem i ens retrobem, molts anys, dins s'esfera de sa pau.

I amb aquest vers, una mica bàmbol, però carregat de bona intenció, se posa la clau a l'acte (Ginard I98I: II5-II6).

Tanmateix, potser sense ser-ne del tot conscient, en l'assaig El cançoner popular de Mallorca, quan parla dels diferents tipus de mètrica i d'estrofa de les cançons tradicionals, Ginard posa un exemple que es pot considerar una autèntica apologia de la violència masclista. La glosa en qüestió, exemple de rima ABAABBA, diu així:

\author{
Garrida t'he de matar \\ si t'encuantr a carreró; \\ no te deixaré xerrar, \\ confessar ni combregar, \\ ni rebre extremunció. \\ I així sabràs, bona amor, \\ què cosa és fer-me penar (Ginard I98I: I29).
}

De fet, hi ha moltes cançons populars plenes de violència envers les dones. Ginard, en una actitud molt pròpia del seu temps, recull aquests poemes tot i la seva cruesa, igualment com també recull nombroses cançons contra els xuetes, els jueus conversos mallorquins. És lògic que, com a folklorista que du a terme una 
feina científica i rigorosa, no censuri aquestes obres. Ara bé, en canvi, mostra reticències davant les cançons eròtiques, que no són ocasionades per la imatge degradant que puguin oferir de la dona o del sexe, sinó per uns escrúpols morals molt propis de la societat puritana de la postguerra. En diverses ocasions, Ginard confessà els seus recels davant la publicació de cançons eròtiques o pornogràfiques, la qual cosa explica l'absència quasi absoluta d'aquestes peces en el seu recull. A més, si la condició de religiós el retreia a l'hora de publicar-les, també havia de coartar molts dels seus informadors en el moment d'ensenyar-li aquestes cançons. No és arriscat suposar que l'autocensura encara devia esser major si l'informador era una dona, però no en tenim cap prova. Així, davant el problema de la censura i de l'autocensura que presentava la publicació de les cançons eròtiques, Francesc de B. Moll li suggerí la possibilitat d'editar-les en alguna revista estrangera de folklore, de manera que passassin desapercebudes a la gent del país. Però Ginard, en una carta del 29 d'octubre de I966 a Moll, refusà aquesta solució i preferí eliminar-les, tot argumentant que, si s'havien censurat passatges dels clàssics a la Fundació Bernat Metge, també es podien suprimir aquestes gloses (Rosselló 2000: I09). Ara bé, com ha observat Miquel Sbert (I999: 65-66), Ginard va incloure algunes cançons eròtiques esparses en els volums II i III del Cançoner popular de Mallorca. ${ }^{2}$

\section{Conclusions}

Rafel Ginard i Bauçà, tot i ser un religiós d'una època en què al nostre país el feminisme era pràcticament inexistent i el masclisme dominava la societat, va manifestar una actitud molt oberta davant el tema de la dona. S'oposà de manera explícita i contundent a les actituds antifeministes i denuncià el domini de l'home sobre la dona. Possiblement, l'admiració per sa mare i per sa germana va tenir molt a veure amb aquest posicionament. En aquest sentit, en la seva obra com a folklorista també va denunciar les actituds masclistes que es poden trobar en les cançons populars mallorquines, reflex del domini de l'home sobre la dona en els diversos àmbits socials. En general, podem pensar que el nostre folklorista formava part d'aquell grup d'homes favorables a la igualtat de la dona i s'oposava al

2 Hem de dir que algunes gloses recollides per Ginard poden tenir un sentit figurat, de contingut eròtic, i un altre de més literal. Ginard hi inclou moltes cançons que, en sentit literal, són ben ingènues, però que, en sentit figurat, tenen un sentit ben sexual. Una d'aquestes podria ser la següent:

Sa meva perdiu va alegre, tota sa nit ha cantat, jo me pens si haurà trobat bon blat, i ha fet sa vega (Ginard I980: 3I).

Curiosament, aquesta cançó prové de Galilea, on només ens consta que el P. Ginard tenia una col-laboradora, Aina Pujol Llabrés, aleshores de catorze anys; però també en recull una variant a Sineu. O aquesta altra cançó, recollida a Felanitx, que diu:

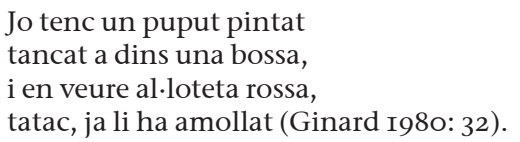

El darrer vers presenta variants molt més explícites: «tot d'una ja treu es cap», «tot d'una vol treure es cap» (Ginard I980: 46). 
«fonamentalisme masculí». Tot i això, però, tampoc no s’escapà de caure en algunes contradiccions envers el feminisme. I, així com va censurar moltes cançons a causa del seu contingut eròtic, en canvi va recollir peces populars d'un marcat caràcter masclista i misogin o que, fins i tot, queien en la violència envers les dones.

Per altra part, les dones foren per a ell una font d'informació importantíssima en la tasca de recollida del cançoner popular mallorquí. Ell mateix ens diu que sa mare, de qui va aprendre la riquesa de la llengua popular, fou una de les principals fonts en la recollida de les cançons, així com de moltes altres tradicions culturals del poble. Ginard lloà les qualitats de les dones com a informadores, perquè, segons ens diu, elles saben més cançons que no els homes. El seu testimoni ens corrobora que la cultura popular — i, per tant, el cançoner- és una cultura feminitzada, en la qual la dona ha jugat un paper fonamental com a transmissora i com a receptora. Així, el nombre de dones que ens consta que col·laboraren en la recollida del cançoner és elevat (I65; 42,I9\%) i, encara que sigui inferior al dels homes (226; 57,8I\%), la seva aportació no fou menys important ni de menor qualitat. Possiblement, és tot el contrari. Les labors que, amb la divisió del treball en el camp i en els pobles, feien les dones facilitaven que, quan les duien a terme, cantassin més que els homes. Per això, Ginard diu que «La musa popular és femenina de nom i de fets» (I98I: 20). Ara bé, aquest coneixement major de les cançons que tenien les dones no implicava que fos més fàcil recollir-les dels seus llavis que no dels dels homes. Sovint el folklorista es trobava amb entrebancs, motivats per tabús i supersticions i, també, pels prejudicis culturals de la família de les informadores. Una situació que, precisament, reflecteix la repressió de la dona i, a més, la menysvaloració envers la cultura tradicional que tenien algunes persones que havien accedit a uns determinats nivells d'ensenyament. 


\section{Referències bibliogràfiques}

Bonino MÉNDEZ, Luis (I998): «Los varones frente al cambio de las mujeres». Lectora. Revista de Dones i Textualitat, núm. 4: 7-22.

CLÚA, Isabel (2008). «¿Tiene género la cultura? Los estudios culturales y la teoría feminista». Dins Género y cultura popular. Estudios culturales I. Bellaterra: Edicions UAB, p. II-27.

GINARD BAUÇÀ, Rafel (I980²): Cançoner popular de Mallorca, volum II. Palma: Editorial Moll.

- (I981²): El Cançoner popular de Mallorca. Palma: Editorial Moll.

- (2003): De com era infant. Sant Joan: Col-lectiu Teranyines.

GONZÁLEZ FERNÁNDEZ, Helena; Isabel ClúA (2OII): «El género que se escribe en la cultura popular». Dins Máxima audiencia. Cultura popular y género. Barcelona: Icaria, p. 7-I4. <http://hdl.handle.net/2445/32925> [data de consulta: abril de 20I7]

Herrero Granado, M. Dolores (I998): «Como agua para aceite: los hombres y la causa feminista». Lectora. Revista de Dones i Textualitat, núm. 4: 37-48.

Holows, Joanne (2005): «Feminismo, estudios culturales y cultura popular». Lectora. Revista de Dones i Textualitat, núm. II: I5-28.

IbEAS VueltA, Nieves (I998): «Hombres y feminismo: resistencias de una antonimia impertinente». Lectora. Revista de Dones i Textualitat, núm. 4: I-5.

Rosselló Bover, Pere (I999): Els camins de la cançó. Vida i obra del P. Rafel Ginard Bauçà. Barcelona: Publicacions de l'Abadia de Montserrat / Universitat de les Illes Balears.

- (2000): «Rafel Ginard i Bauçà i Francesc de Borja Moll, "autors” del Cançoner popular de Mallorca». Publicacions des Born, núm. 8: 95-IIo.

Sbert I GARAU, Miquel (I999): «El P. Rafel Ginard i el Cançoner popular». Dins Sant Joan, la meva terra. Sant Joan: Col-lectiu Teranyines, p. 59-80.

VALRIU LlinÀs, Caterina (2008): «La dona en el Cançoner popular de Mallorca». Dins Paraula viva. Articles sobre literatura oral. Barcelona: Publicacions de l'Abadia de Montserrat / Edicions UIB / Institut d'Estudis Baleàrics, p. 336-355. 